\title{
Contents
}

\section{FPCA-II Opening Comments}

André Heck ....................................... 1

2 Astronomical Publishing: Yesterday, Today and Tomorrow

John Huchra ............................................ 11

3 The Emerging Scholarly Brain

Michael J. Kurtz................................. 23

4 Communicating Astronomy Beyond IYA2009

Richard Tresch Fienberg ........................... 37

5 Trends in Scientific Publishing at Springer

Guenther Eichhorn ............................... 47

6 Publishing Astronomy and Astrophysics: Article

Numbering, Electronic First

Marie-Louise Chaix ................................. 57

7 The Future of the ASP Conference Series

Joseph B. Jensen, Jonathan Barnes, J. Ward Moody,

and Paula Szkody

8 Astronomical Publication Rates in the US, UK, and Europe Helmut A. Abt................................. 77

9 Fully Digital: Policy and Process Implications for the AAS Chris Biemesderfer................................ 83

10 Open Access: Current Status, AAS Perspectives

Kevin B. Marvel and Chris Biemesderfer ...................... 91

11 Astronomy Librarian - Quo Vadis?

Jill Lagerstrom and Uta Grothkopf ............................ 101 
12 Telescope Bibliometrics 101

Uta Grothkopf and Jill Lagerstrom

13 Progress on the 'Declaration Concerning the Evolving Rôle of Libraries in Research Centres'

Terence J. Mahoney

14 Finding Your Literature Match - A Recommender System Edwin A. Henneken, Michael J. Kurtz, Alberto Accomazzi, Carolyn Grant, Donna Thompson, Elizabeth Bohlen, Giovanni Di Milia, Jay Luker, and Stephen S. Murray ............................ 125

15 Linking Literature and Data: Status Report and Future Efforts Alberto Accomazzi.

16 FPCA-II Concluding Remarks

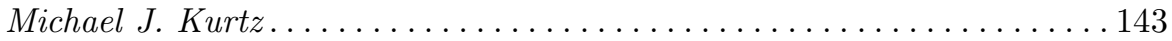

Future Professional Communication in Astronomy II . . . . . . . 147 